\title{
DSP Tabanlı Fırçasız Doğru Akım Motorunun Bulanık Mantık ile Kontrolü
}

\author{
Ali Bahadır ${ }^{*}$, Ömer Aydoğdu² \\ 1* İstanbul Teknik Üniversitesi, Elektrik Elektronik Fakültesi, Elektronik ve Haberleşme Mühendisliği Bölümü, İstanbul, Türkiye, (ORCID: 0000-0002-8322-2527), \\ bahadiral@itu.edu.tr \\ ${ }^{2}$ Konya Teknik Üniversitesi, Mühendislik ve Doğa Bilimleri Fakültesi, Elektrik Elektronik Mühendisliği Bölümü, Konya, Türkiye (ORCID: 0000-0003-0815-0356), \\ oaydogdu@ktun.edu.tr
}

(İlk Geliş Tarihi 9 Şubat 2021 ve Kabul Tarihi 4 Nisan 2021)

(DOI: 10.31590/ejosat.877627)

ATIF/REFERENCE: Bahadır, A. \& Aydoğdu, Ö. (2021). DSP Tabanlı Fırçasız Doğru Akım Motorunun Bulanık Mantık ile Kontrolü. Avrupa Bilim ve Teknoloji Dergisi, (23), 427-434.

$\ddot{O} z$

Bu çalışma, yeni tip bir Dijital Sinyal İşlemci (DSP) tabanlı Fırçasız Doğru Akım Motoru'nun (FDAM) bulanık mantık ile kontrolüne odaklanmıştır. Fırçasız doğru akım motorunun kontrol yapısı, FDAM MATLAB/Simulink modeli ve FDAM bulanık kontrol MATLAB/Simulink modeli gerçekleştirilmiştir. Hız akım bilgilerinin ölçümü ve hesabının yapılması koda aktarılması gerçekleştirilmiştir. Simülasyon sonuçları elde edilmiş. Gerçek sistem üzerinde deneyler yapılmış ve simülasyon sonuçları ile deney sonuçlarının paralellik gösterdiği ve bulanık mantık kontrol algoritmasının çok verimli bir şekilde çalıştığı tespit edilmiştir.

Anahtar Kelimeler: Fırçasız Doğru Akım Motoru, Simulink modeli, DSP, Gerçek Zamanlı, Gömülü Sistem, Bulanık Mantık.

\section{Fuzzy Logic Control of DSP Based Brushless Direct Current Motor}

\begin{abstract}
This study focuses on the control of a new type of Digital Signal Processor (DSP) based Brushless DC (BLDC) motor with fuzzy logic. The control structure of brushless direct current motor, BLDC MATLAB/Simulink model and BLDC fuzzy control MATLAB/Simulink model are realized. The measurement and calculation of the speed flow information were transferred to the code. Simulation results are obtained. Experiments have been carried out on the real system and it has been determined that the simulation results and the experiment results are parallel and the fuzzy logic control algorithm works very efficiently.
\end{abstract}

Keywords: Brushless Direct Current Motor, Simulink model, DSP, Real Time, Embedded System, Fuzzy Logic.

\footnotetext{
*Sorumlu Yazar: bahadiral@itu.edu.tr
} 


\section{Giriş}

Günümüzde artan enerji ihtiyacı ve fosil yakıtlarının azalması, insanları alternatif enerji kaynakları aramaya ve kullanmaya teşvik etmektedir. Ayrıca fosil yakıtların yakılmasıyla oluşan karbondioksit, metan, karbonmonoksit, kükürtdioksit gibi artık gazlar atmosferi kirletmekte ve küresel 1sınmaya sebep olmaktadır (Abdulhamitbilal E. (2010); Tutelea, L.; I. Boldea, I., (2007); Ustun, O., Yilmaz, M., Gokce, C., Karakaya, U., Tuncay, R. N., (2009)).

Günümüzde fosil yakıtların kullanımını azaltmak adına elektrikli araçlara olan ilgi ve bu alandaki yatırımlar artmaktadır. $\mathrm{Bu}$ araçların en büyük problemi olan yakıt ikmali ise gelişen akü teknolojisi ve hızlı şarj teknikleri sayesinde aşılmaya çalışılmaktadır. (Abdulhamitbilal E. (2010), Tutelea, L.; I. Boldea, I., (2007), Ustun, O., Yilmaz, M., Gokce, C., Karakaya, U., Tuncay, R. N., (2009)).

Elektrikli araç konusunda olsun diğer robotik, tıp elektroniği, iklimlendirme sistemleri, endüstriyel çözümler, çamaşır makinası, buzdolabı, bulaşık makinası, drone, insansız kara, hava, denizaltı araçları gibi birçok alanda yapılan çalışmalarda verimliliğinin yüksek olması sebebi ile Fırçasız Doğru Akım Motoru (BLDC) ve Kalıcı Mıknatıslı Senkron Motor (PMSM) tercih edildiği görülmektedir. (Markovic, M., Hodder, A., Perriard, Y. (2009); Zhao, L., Ham, C., Zheng, L., Wu, T., Sundaram, K., Kapat, J., Chow, L. (2007); Magnetics, 43(6), 2528-2530; Tuncay, R.N., Üstün, O., Yılmaz, M., Gökce, C., Karakaya, U.(2011); Nair, S.S., Nalakath, S., Dhinagar, S.J. (2011))

FDAM ve PMSM motorların rotorlarında sabit miknatıs olması sebebiyle asenkron motora göre kayıları az olacağından verimleri yüksektir. Kayıplar azaldığından sıcaklıkta azalır. Kullanılan mıknatısların maliyetlerinden dolayı fiyatları asenkron motora göre daha yüksek olmasına rağmen eskiye nazaran fiyatları düşmektedir. Kilogram başına güç değerleri yüksek olduğundan asenkron motorlara göre daha hafiftirler ve daha az yer kaplarlar. $\mathrm{Bu}$ motorlar diğer motorlara nazaran çok daha sessizdirler, soğutması kolaydır, güvenilir çalışma ortamı sağlar, yüksek hızlarda çalışma imkânı sağlar, firçasız yapıları sebebiyle ark oluşturmaz, karbon tozları oluşmaz, uyarma akımına ihtiyaç duymaz. Ancak kontrolü daha zordur, kontrol devresi karmaşıtır, pozisyon sensörlerine ihtiyaç duyarlar. (Nair, S.S., Nalakath, S., Dhinagar, S.J. (2011); Park, S.J., Park, H.W., Lee, M.H., Harashima, F. (2000); Zarko, D.,Ban, D., Lipo, T.A. (2006); Rahim, N.A.,Hew Wooi Ping, H.W., Tadjuddin, M. (2007))

Çalışmada ilk adım olarak sistem fırçasız doğru akım motorunun simülasyon modeli elde edilmiş ve ardından motor sürücü sisteminin pratik uygulaması yapılmıştır. Önerilen tahrik sisteminin esnekliği floating point olan bir DSP kullanılarak artırılmıştır. Önerilen kontrol algoritması, Code Composer Studio Compiler uygulamasında programlanmıştır ve üç fazlı tam kontrollü köprü dönüştürücünün MOSFET'leri çalıştırmak için gereken tetikleme darbelerini üretir. Fırçasız doğru akım motoru tam kontrollü sürücü devresini sürmek için gerekli PWM sinyallerini TMS320F28069 DSP komütasyon tablosuna uygun şekilde üretmektedir. Önerilen sürücünün performansını analiz etmek için sürücü sisteminin matematiksel bir modeli geliştirilmiştir. Simülasyon modeli Matlab/Simulink ortamı kullanılarak geliştirilmiştir. Simülasyon ve deneysel sonuçlar, geliştirilen sürücü çalışmasının etkinliğini göstermiştir.
Bu çalışmada, Matlab/Simulink blok setlerini kullanarak DSP tabanlı kontrol yönteminin tasarımını, otomatik model tabanlı gerçek zamanlı gömülü kod üretimini, yürütülebilir kodun TMS320F28069 DSP kartına indirilmesini içeren hızlı prototipleme ve bulanık mantık kontrol algoritması sunulmuştur. DSP ile entegre Matlab/Simulink tabanlı geliştirme platformu, DSP algoritmalarının tasarım doğrulaması için yararlı bir geliştirme aracı sağlar. Deneysel sonuçlar, PWM kontrol yapısı kullanılarak geliştirilen kodun oldukça verimli olduğunu ve geliştirme döngüsü süresinin büyük ölçüde azaldığını göstermektedir. Başka bir deyişle düşük geliştirme maliyetiyle hızlı prototipleme sürecinin başarılı olduğu gözlemlenmiştir.

Alan etkili (Hall effect) sensör sinyalleri, rotor konumunu algılamak için kullanılır. Bu sensör sinyalleri, faz akımı algılama sinyali, hız komutu (referans hız) dijital denetleyicinin girdisidir. Hem açık çevrim hem de kapalı çevrim hız ve akım kontrol döngüsü sistem içerisinde başarı ile sonuç vermiştir. Giriş komutu, geri besleme komutu ve kontrol algoritmasına göre, DSP tarafından üretilen her faz için PWM darbeleri MOSFET sürücüsüne verilir. Sürücünün çıkışı FDA motorun statörüne verilen; üç fazlı tam köprü invertörde kullanılan altı MOSFET güç anahtarının karşılık gelen kapısına verilmesi gereken 6 bağımsız PWM darbesidir. Tahrik performansı, başlatma, hızın tersine çevrilmesi ve yük karışıklığı için incelenmiştir. Sistem yanıtı, normal komutasyona göre PWM sinyalleri ile kontrole nazaran bulanık denetleyici kullanımı çok daha başarılı olmuştur. FDAM'ın istenilen referans hız değerine ulaşması çok çok kısa sürede gerçekleşmektedir.

\section{Materyal ve Metot}

\subsection{Fırçasız Doğru Akım Motorunun Kontrolü ve Modeli}

Fırçasız doğru akım motorunun kontrolü, motorun akım değerinin kontrolü ve rotor ve stator akı senkronizasyonu şeklinde iki bağımsız kısma ayrılabilir. FDAM üç fazlı -AA dönüştürücüde alıgılayıcılardan, örneğin hall-effect sensörlerinden veya algılayıcısız kontrol yapısında, örneğin sıfır geçiş noktalarının tespitinden konum bilgisi alınır ve tablo1 ve 2 . de açıklandığı gibi komütasyon sırası ve anahtarlama çifti zamanlamaları belirlenerek akı senkronizasyonu gerçekleştirilir. Anahtarlama elemanlarına uygulanacak sinyal ve açı aralıkları faz sayısına bağlı olarak tespit edilir, bu açılara uygun darbe genişlik modülasyonu (PWM) tetikleme sinyalleri elde edilir veya histerisiz kontrol yapılarak akım kontrolü gerçekleştirirlmiş olur.

Moment Titreşimleri: Komutasyon sırasındaki moment dalgalılığı (Akımın azalması ve yükselmesi), diş etkisi momenti (motor geometrisi, mıknatıs yay açısı), endüklenen gerilimdeki bozukluklar (doyma, endüvi reaksiyonu, üretim hatası, demagnetizasyon, kaçak akı), akım dalgalanmaları (Histerisiz kontrol) gibi etkilerden oluşur. $\mathrm{Bu}$ dalgalanmaların dikkate alınmaması endüklenen gerilimin daha temiz net bir trapezoidal şekile sahip olması anlamına gelir.

Üç faz için altılı anahtarlama elemanı olarak MOSFET, IGBT, GaN veya SiC kullanılabilir. Çalışma gerilimi, akımı, verimliliği, anahtarlama kayıpları, termal dayanım, termal üst alt sınırlara çıkabilme, maliyet gibi parametrelere bağlı olarak seçim yapılır. Seçilen anahtarlama elemanının çalışma yapısına göre bu elemanı sürecek sürücü bir devre tasarlanır. Bu sistemin PWM anahtarlama çıkışlarını, alan etkili sensörlerden alınan konum bilgisine göre verecek bir mikrodenetleyicinin seçilmesi 
gerekecektir. $\mathrm{Bu}$ çalışmada mikrodenetleyici olarak, hızlı otomotiv standartlarına uygun floating point Texas Instrument firmasına ait TMS320F28069 DSP işlemcisi tercih edilmiştir.

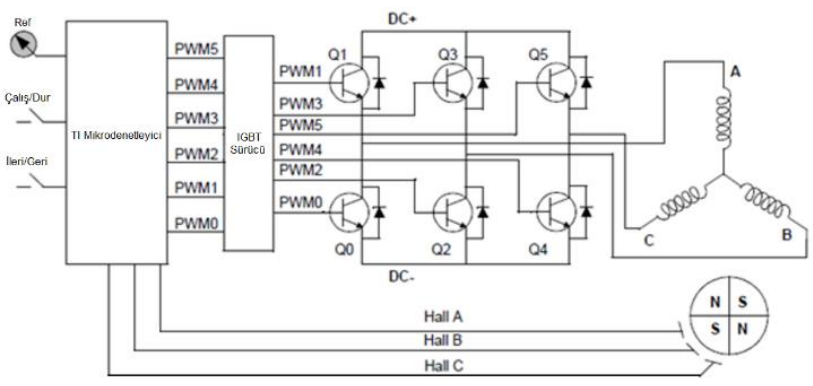

Şekil 1. Faz akımları ve anahtarlama açı değerleri

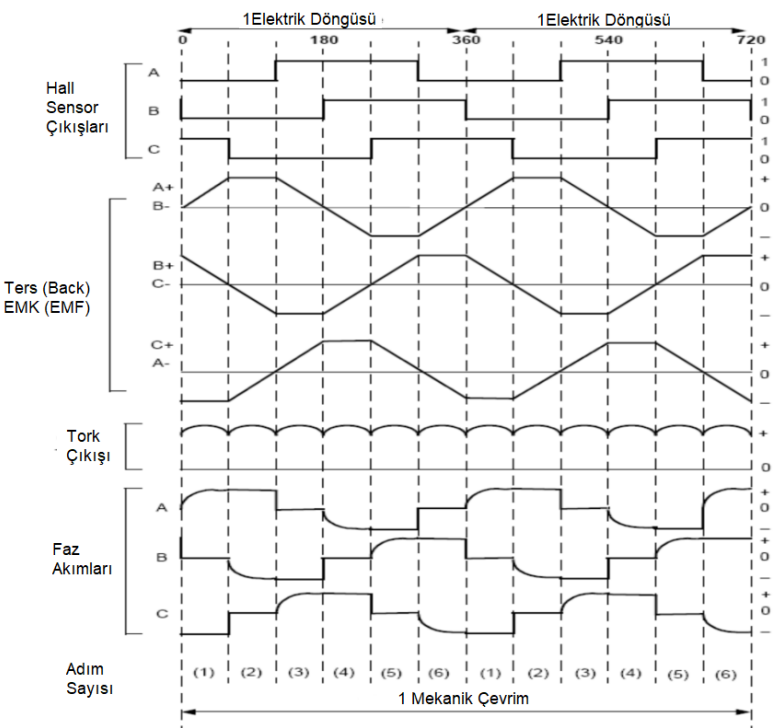

Şekil 2. Alan etkili (hall effect) sensör çıkışları, faz akımları ters EMK sinyalleri ve adımları

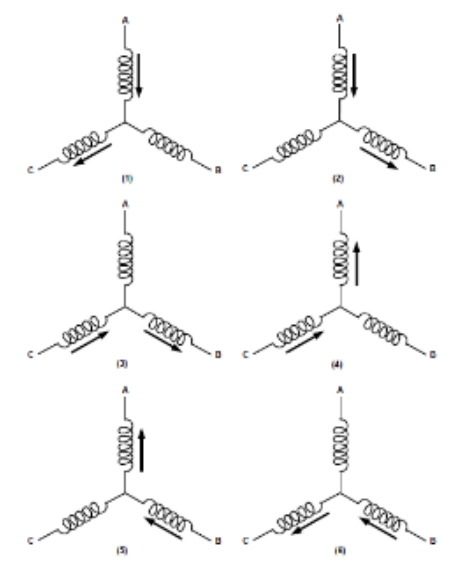

Şekil 3.Her bir adım için sargı uyarıları faz akımları

Her rotor kutup çifti için bir elektrik çevrimi tamamlanmalıdır. Saat yönünde veya saat yönünün tersinde motoru çevirmek için öncelikle hall-effect sensörden gelen o anki bilgiyi okumalıyız, konumumuzu belirlemeliyiz. Bu bilgiye göre hangi yönde döndürmek istiyor ise Tablo 1. ve Tablo 2'deki tablolarda belirtilen anahtarlara PWM sinyali uygulanır ve bu tablodan ikinci verilmesi gerekli anahtarlama elemanlarının
PWM'leri uygulanır. Bu döngü bu şekilde sürdürülerek motor istenen yönde çevrilmiş olur.

Tablo 1. FDAM motoru saat yönünde döndürmek için uyartım sirası

\begin{tabular}{|c|c|c|c|c|c|c|c|c|}
\hline \multirow{2}{*}{$\begin{array}{c}\text { Adımlar } \\
\#\end{array}$} & \multicolumn{3}{|c|}{ Hall Sensör Girișleri } & \multirow{2}{*}{\multicolumn{2}{|c|}{ Aktif PWM'ler }} & \multicolumn{3}{|c|}{ Faz Akımları } \\
\hline & A & B & c & & & A & B & c \\
\hline 1 & 0 & 0 & 1 & \begin{tabular}{|l|} 
PWM1(Q1) \\
\end{tabular} & PWM4(Q4) & DC+ & Off & DC- \\
\hline 2 & 0 & 0 & 0 & PWM1(Q1) & PWM2(O2) & $\mathrm{DC}+$ & DC. & Otf \\
\hline 3 & 1 & 0 & 0 & PWM5(Q5) & PWM2(O2) & Oft & DC. & $\mathrm{DC}+$ \\
\hline 4 & 1 & 1 & 0 & PWM5(Q5) & PWMO(Q0) & DC. & Oft & $\mathrm{DC}+$ \\
\hline 5 & 1 & 1 & 1 & PWM3(Q3) & PWMO(Q0) & DC- & $\mathrm{DC}+$ & Off \\
\hline 6 & 0 & 1 & 1 & PWM3(Q3) & PWM4(Q4) & OII & $\mathrm{DC}+$ & DC- \\
\hline
\end{tabular}

Tablo 2. FDAM motoru saat yönünün tersi döndürmek için uyartım sirası

\begin{tabular}{|c|c|c|c|c|c|c|c|c|}
\hline \multirow{2}{*}{$\underset{\#}{\text { Adımlar }}$} & \multicolumn{3}{|c|}{ Hall Sensör Girişleri } & \multirow{2}{*}{\multicolumn{2}{|c|}{ Aktif PWM"ler }} & \multicolumn{3}{|c|}{ Faz Akımları } \\
\hline & A & B & c & & & A & B & c \\
\hline 1 & 0 & 1 & 1 & PWM5(Q5) & PWM2(Q2) & Off & DC- & $\mathrm{DC}+$ \\
\hline 2 & 1 & 1 & 1 & PWM1(Q1) & PWM2(Q2) & $\mathrm{DC}+$ & DC- & Off \\
\hline 3 & 1 & 1 & 0 & PWM1(Q1) & PWM4(Q4) & $\mathrm{DC}+$ & Off & DC. \\
\hline 4 & 1 & 0 & 0 & PWM3(Q3) & PWM4(Q4) & Off & $\mathrm{DC}+$ & DC- \\
\hline 5 & 0 & 0 & 0 & PWM3(Q3) & PWMO(Q0) & DC- & $\mathrm{DC}+$ & Off \\
\hline 6 & 0 & 0 & 1 & PWM5(Q5) & PWMO(Q0) & DC- & Off & $\mathrm{DC}+$ \\
\hline
\end{tabular}

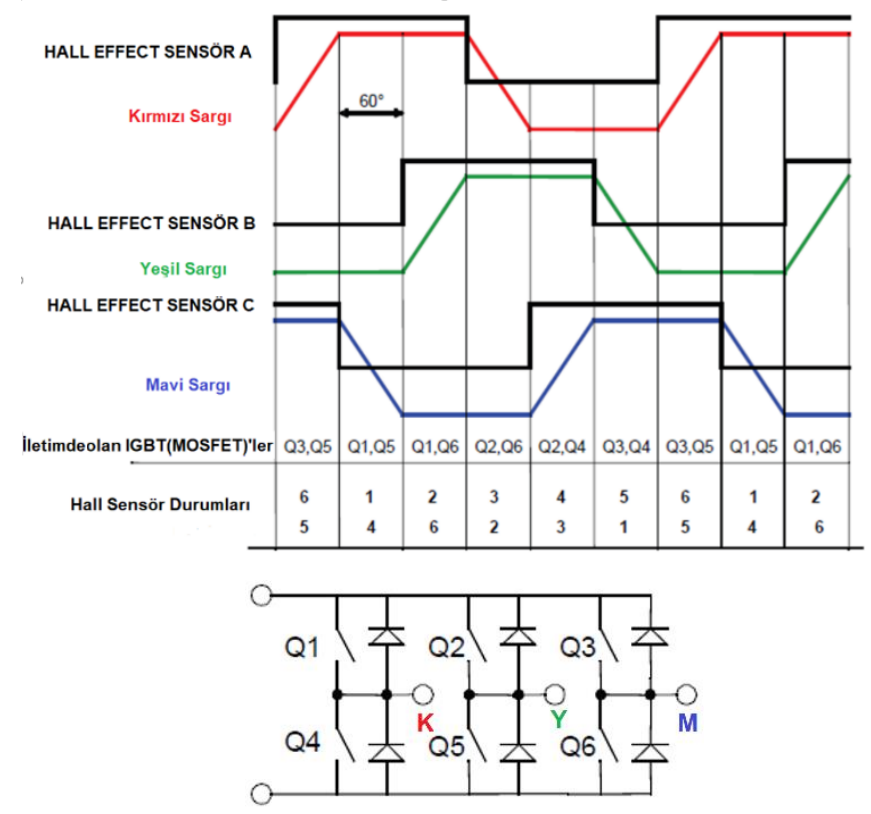

Şekil 4. BEMF ve Hall Sensörü Çıkışları Arasındaki İlişki

Fırçasız doğru akım motorları, rotorunda bulunan sürekli mıknatıslar ile iletken akımlarının etkileşimi sonucu endüklenen momentin enerji dönüşümünü oluşturan elektrik makinasıdır. Fırçalı doğru akım motorlarında rotor akımının kollektör tarafindan değişimi, tek yönlü düzgün moment ile oluşturulurken firçasız doğru akım motorlarında ise rotordaki mıknatısın her kutup değişiminde statordaki iletkenlerin akım yönleri güç yarı iletken anahtarlama elemanları ile değiştirilir. Böylece komütasyon ile kontrol edilmiş doğru akım makinası gerçekleştirilmiş olur (Ustun, O., Yilmaz, M., Gokce, C., Karakaya, U., Tuncay, R. N., (2009)).

Texas Instrument firmasina ait TMS320F28069 DSP işlemcisi ile FDAM PWM sinyalleri üretilerek standart kontrol algoritması ile çalıştırılmıştır. Kp, Ki, Kd değerlerini değiştirerek moment, devir değişimleri ve referans değeri hata değeri ve hatası gözlemlenmektedir. MATLAB Simulink'te gerçekleştirilen bulanık kontrol yapısını simulink üzerinden doğrudan floating point Texas Instrument firmasına ait TMS320F28069 işlemcisine yüklenmiş ve sistem gerçek zamanlı olarak çalıştırılmıştır. Hem denenen güç katı hem de denenen kontrol yazılımının gömülü bir 
sisteme aktarılması gerekmiştir. Bazi gömülü sistem yapılarını MATLAB Simulink o işlemciye ait emülatör üzerinden doğrudan görmekte ve simulink blok diyagramlı yapıyı hex dosyasına çevirerek gömülü işlemciye yükleyebilmektedir. MATLAB Simulink üzerinden gömülü sisteme geçmenin en kolay yolu budur. Ancak, bu yapıda yazılım çok yavaş çalışmakta yazılımın içinde sistemi yavaşlatan birçok konfigürasyon ve kullanılmayan include dosyaları bulunmaktadır. Gömülü işlemcinin yapısına uygun bir şekilde tasarlanan kontrol algoritmasının $C$ gibi güçlü hızlı bir dil ile baştan yazılması sistemin çok hızlı, kararlı ve verimli çalışmasını sağlamaktadır. Bir de tasarlanan kontrol yazılımı emniyetin, güvenliğin en üst olduğu otomobil, İHA, uçak gibi sistemlerde kullanılıyor ise bu konu çok daha önem arzetmektedir. Dört farklı gömülü sistem yapısı seçilmiş bu mikrodenetleyicilerin yapısına göre kontrol algoritmaları yeniden C dilinde yazılmıştır ( TMS320F28069 Data Manual. (2004).

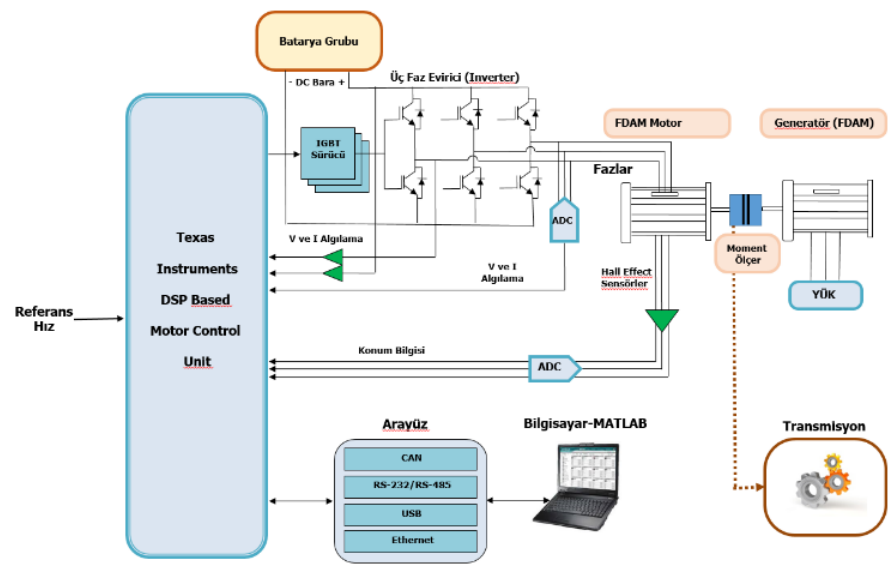

Şekil 5. DSP Temelli FDAM Kontrol Genel Blok Diyagramı

FDAM'nin MATLAB Simulink modeli gerçekleştirilmiştir. MATLAB R2018b versiyonu ile bu tasarımlar gerçekleştirilmiştir (Simulink, Simulation and Model-Based Design (2020)).

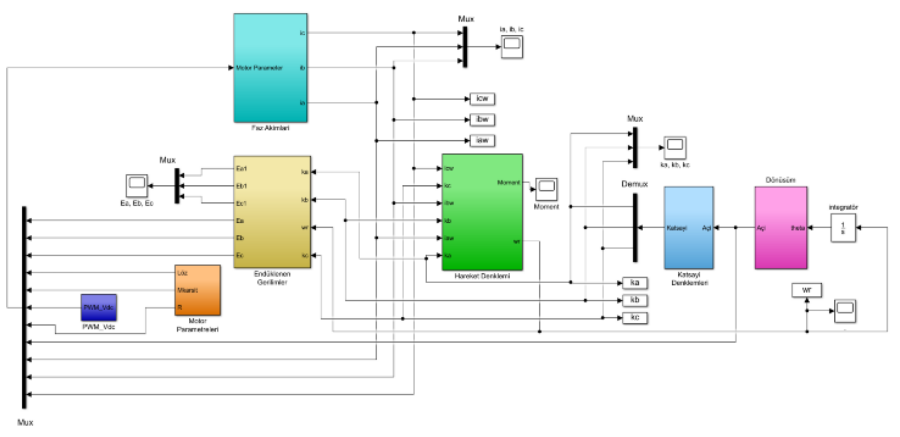

Şekil 6. FDAM MATLAB Simulink Modeli

Fırçasız Doğru Akım Motorunun matematiksel ifadesi 1 nolu denklem'de görülmektedir.

$$
\frac{d}{d t}\left[\begin{array}{l}
i_{1}(t) \\
i_{2}(t) \\
i_{3}(t)
\end{array}\right]=\left[\begin{array}{ccc}
-\frac{R}{L} & 0 & 0 \\
0 & -\frac{R}{L} & 0 \\
0 & 0 & -\frac{R}{L}
\end{array}\right]\left[\begin{array}{l}
i_{1}(t) \\
i_{2}(t) \\
i_{3}(t)
\end{array}\right]+\left[\begin{array}{ccc}
-\frac{1}{L} & 0 & 0 \\
0 & -\frac{1}{L} & 0 \\
0 & 0 & -\frac{1}{L}
\end{array}\right] \cdot\left\{\left[\begin{array}{l}
V_{1} \\
V_{2} \\
V_{3}
\end{array}\right]-\left[\begin{array}{l}
e_{1}(t) \\
e_{2}(t) \\
e_{3}(t)
\end{array}\right]\right\}
$$

FDAM kontrolör tasarımı gerçekleştirilmiştir. Fazların elektriksel momentleri, EMK ve akım değerleri gözlemlenmiştir.

\subsection{FDAM'ın Bulanık Mantık Kontrolü}

Klasik kontrol mantığının (PI-PID) yetersiz kaldığı durumlarda sistem kontrolünde kullanılabilecek en iyi akıllı kontrol yöntemlerinden biri bulanık mantık kontrol (Fuzzy Logic Control) yöntemidir. Bulanık mantık kontrol sistemleri yapısı itibari ile lineer olmayan, insan alg1 ve deneyiminin sisteme yansitılması gerektiği konularda, problemin matematiksel modelinin tasarlanamadığı ya da çok zor tasarlandığı durumlarda iyi bir performans veren ve tercih edilen bir yöntemdir. İnsan algısının dilde kullanılan şekliyle ifadeleri kullanan bulanık mantık kontrol yapıları üç temel kısımdan meydana gelir:

1. Bulanıklaştırma (Fuzzification): Kontrol sistemini tasarlayan kişinin o sistem için tespit ettiği ve kullanmak istediği parametrelerin yani bilgilerin üyelik fonksiyonları türünden ifade edilmesi işlemidir.

2. Kural Tabanı (Fuzzy Inference): Kontrol sistemini tasarlayan kişinin o sistem için edinmiş olduğu tecrübe ve bilgi birikimine göre şartlara uygun kuralların oluşturulması işlemidir.

3. Durulaştırma (Defuzzification): Sistem içerisinde kullanılan bulanık mantık değerlerinin tekrar insan algısına uygun kesin değere çevrildiği işlemdir.

Fırçasız doğru akım motorunun lineer olmayan karmaşık, ayrıntılı matematik modelinin oluşturulmadan, buna gerek duyulmadan uygun üyelik fonksiyonları ve kural tabanı tabloları oluşturularak bulanık mantık kontrolörü ile basit, hızlı cevap ve karar verebilen bir yap1 oluşturulabilmektedir. $\mathrm{Bu}$ yöntem ile fırçasız doğru akım motoru içinde hız kontrolü gerçekleştirilebilir.

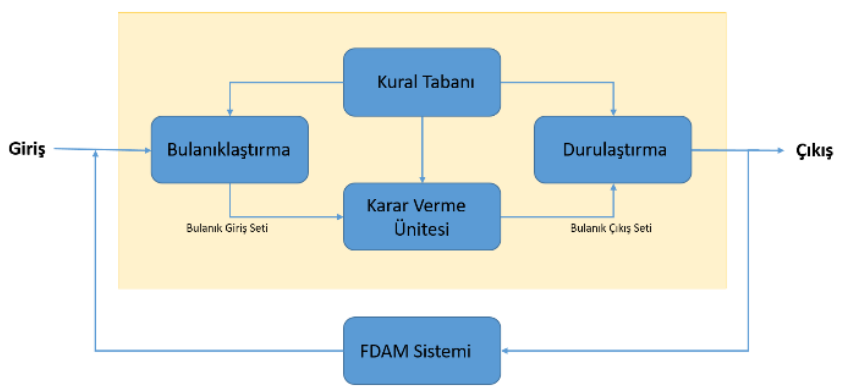

Şekil 7. Bulanık mantık kontrol yapısı blok diyagramı

FDAM bulanık mantık kontrolü MATLAB R2018b Fuzzy Logic Toolbox'ı kullanılarak tasarlanmıştır (IQ Math on the Texas Instruments TMS320C28x DSP. (2004)).

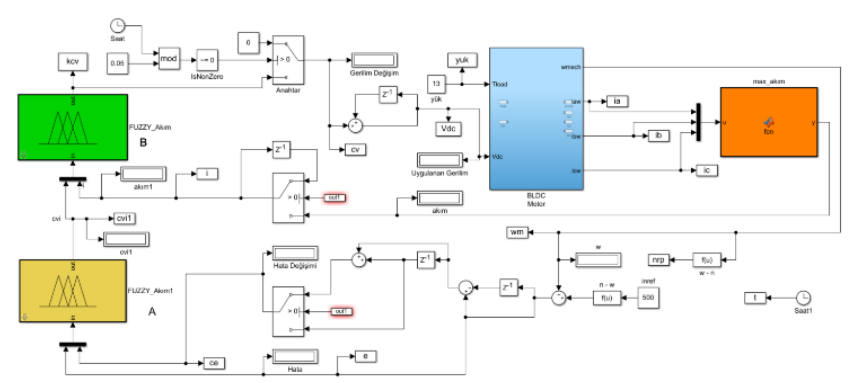

Şekil 8. FDAM bulanık mantık kontrol MATLAB simulink modeli

Bulanık mantık kontrol yapısında giriş değerleri bulanıklaştırma, kontrol ve durulaştırma aşamalarından geçer. 
Bulanık kontrolde kural tabanı oluşturulur, üyelik fonksiyonları hazırlanır. Bir elemanın bir alt kümeye olan yakınlığının 0 ile 1 arasında bir değerle ifade etme işine üyelik fonksiyonu diyoruz. Kural tabanındaki kurallara uyarak eldeki bilgilerin bulanık değerlere çevrilmesi işlemine bulanıklaştırma diyoruz. Giriş değerleri, üyelik fonksiyonları kullanılarak kural tabanı sonrası en uygun değeri çıktı olarak verir. Bulanıklaştırma işlemi, üyelik fonksiyonlarının belirlenmesi ile şekil 9'da akıma ilişkin üyelik fonksiyonları (i), şekil 10'da hesaplanan ve uygulanan gerilimlerin değişimine ilişkin üyelik fonksiyonları (cvi), şekil 11 'de hız hatasına ilişkin üyelik fonksiyonları (e), şekil 12'de hız hatasının değişimine ilişkin üyelik fonksiyonları (ce) gibi gerçekleştirilmiştir.

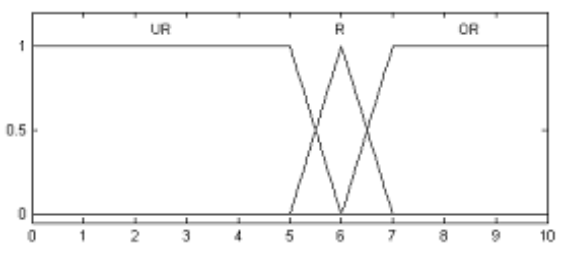

Şekil 9. Akıma ilişkin üyelik fonksiyonları (i)

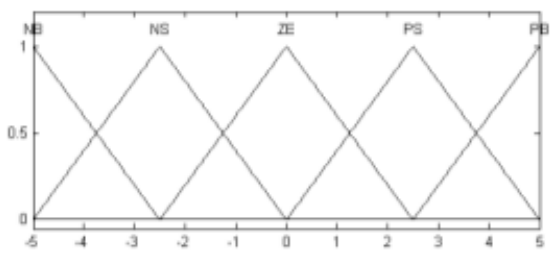

Şekil 10. Hesaplanan ve uygulanan gerilimlerin değişimine ilişkin üyelik fonksiyonları (cvi)

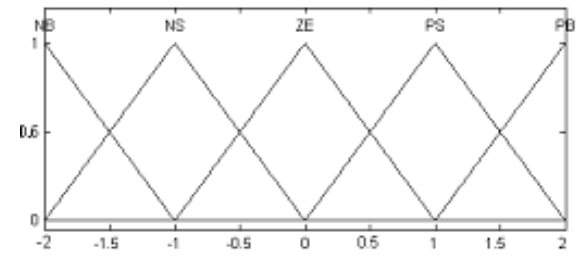

Şekil 11. Hız hatasına ilişkin üyelik fonksiyonları (e)

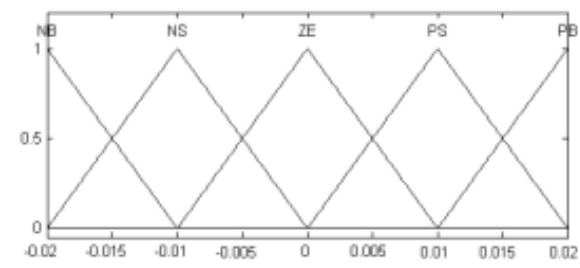

Şekil 12. Hız hatasının değişimine ilişkin üyelik fonksiyonları (ce)

FDAM Bulanık mantık kontrol yapısının belirlenen kural tabanları Tablo 3' de gösterilmiştir. (Moshiri B. and Rashidi F.(2004))

Tablo 3. Bulanık Kontrolör hız ve akım kuralları

\begin{tabular}{|c|c|c|c|c|c|}
\hline ce $\backslash$ e & NB & NS & ZE & PS & PB \\
\hline NB & NB & NB & NB & NS & NS \\
\hline NS & NB & NB & NS & NS & NS \\
\hline ZE & NB & NS & ZE & PS & PB \\
\hline PS & PS & PS & PS & PB & PB \\
\hline PB & PS & PS & PB & PB & PB \\
\hline
\end{tabular}

\begin{tabular}{|c|c|c|c|c|c|}
\hline cvi & NB & NS & ZE & PS & PB \\
\hline UR & NB & NB & NB & NS & NS \\
\hline R & NB & NB & NS & NS & NS \\
\hline OR & NB & NS & ZE & PS & PB \\
\hline
\end{tabular}

\subsection{Hız, Akım ilgilerinin Ölçülmesi}

FDAM'ın alan etkili (hall effect) sensör bilgilerine göre oluşturulan komutasyon lojik işaretleri DSP'ye C dilinde yazılan kontrol algoritmasına yüklenmiş ve oluşturulan DA-AA dönüştürücü ile motor açık çevrim çalıştırılmıştır. Bu aşamada girilen çalışma oranına karşılık ortalama gerilim değiştirilerek motor farklı hızlarda sürülmüştür.

FDAM parametrelerine göre tasarlanan tork kontrolü algoritması çalıştırılmıştır. Tork kontrolü yapısındaki en büyük problemi çalışılan motorun küçük akımlarla çalışması ve bu düşük akımın algılanması sırasında sisteme gelen gürültülerinin etkisinin artmasıdır. Akım kontrolörlü sistemde, FDAM'ın girilen referans akım değerini izlemeye çalıştığı bir yapı söz konusudur. FDAM yüklendiğinde, kontrolör, motor referans akımını takip edilebilmesi için hızını azaltmakta ve akımını sabit tutmaya çalışmaktadır. Basit bir şekilde hız, akım kontrolör yapısının blok diyagramı şekil 13'de görülmektedir.

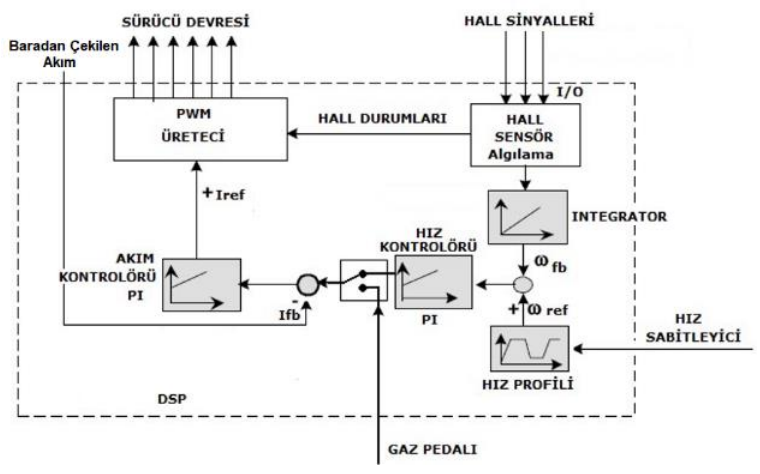

Şekil 13. DSP ile hız akım ölçme blok diyagramı

Akım okumalardaki gürültüler nedeniyle hız kontrol sisteminde, kaskat yapı yerine daha basit bir sistem kullanılmıştır. $\mathrm{Bu}$ durumda akım kontrol altında tutulmadığı için hız referansı belli bir rampa işareti izleyerek artmakta ve azalmakta dolayısıyla akımdaki ani sıçramalara izin verilmemektedir. Ancak akım maksimum değeri geçtiğinde anahtarlama kesilmekte ve sistem korumaya alınmaktadır. $\mathrm{Bu}$ çalışmada iki farklı motor ile çalışılmıştır. Bunlar Nema 17 Fırçasız Doğru Akım Motoru ve Moog NC23 Fırçasız Doğru Akım Motoru'dur.

Hız ölçümü FDAM'ın alan etkili sensörlerinden gelen verilere göre yapılmıştır. Alan etkili sensör verileri DSP'nin "capture" pinleri ile alınıp değerlendirilmiştir. Capture özelliği ile aynı zamanda bir alan etki sensörünün iki yükselen kenar arasındaki mesafe saydırılarak hız verisi elde edilmiştir. FDAM'da bulunan üç adet alan etkili sensörün her biri, bir devirde kutup çifti sayısı (p) kadar darbe gönderir. DSP'nin 'capture' birimi ile iki yükselen kenar arası mesafe DSP saat darbeleriyle orantılı olarak saydırılabilir.

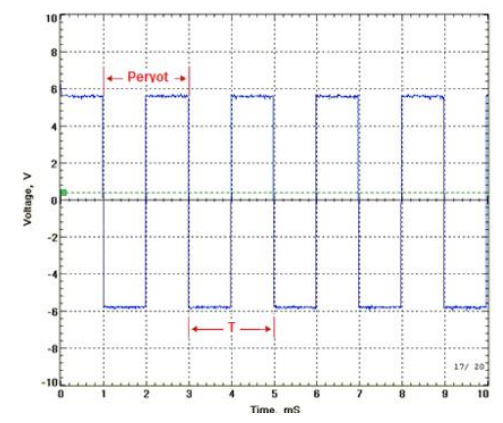


Şekil 14. Alan etkili (hall-effect) sensör çıkış sinyali

Şekil 14'de görüldüğü gibi alan etkili sensör çıkışının iki düşen kenarı arası veya iki yükselen kenarı arası mesafe DSP'de T olarak tanımlanmıştır. FDAM'ın devir sayısı;

$n=\frac{f_{c l k} \cdot 60}{p} \cdot \frac{1}{T}[r p m]$

Burada,

fclk: DSP'nin çalışma frekansı,

p : motorun kutup çifti sayısıdır.

Akım ölçümü yapılırken birinci yöntem olarak; DA-bara'ya bağlı şönt direnç üzerindeki gerilim düşümü analog porttan okunmuştur. Devre topolojisinde kontrol devresi ile güç katı referansları birbirinden farklı olduğu için, fark kuvvetlendirici kullanılmıştır.

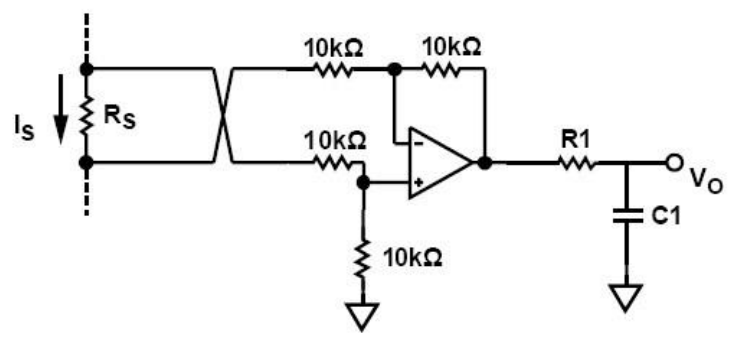

Şekil 15. Akım algılama devresi

Fark kuvvetlendiricisinin kazancı 1 seçilerek, çıkış gerilimi direnç üzerindeki gerilim düşümü olacaktır.

$V_{o}=i_{s} \cdot R_{S}$

Akımın ölçülmesinde çıkış, anahtarlama gürültüleri başta olmak üzere çeşitli birçok gürültüden etkilenmektedir. Bunu önlemek için devre çıkışına kesim frekansı akım çevrimi örnekleme frekansının yaklaşı 1.2 katı olan bir RC filtresi eklenmiştir.

$$
f_{c}=\frac{1}{2 \pi R_{1} C_{1}}
$$

Yukarıdaki denkleme göre filtre direnç ve kondansatörünün değeri belirlenebilir.

Daha yüksek güçler için bu yapı yerine ikinci yöntem olarak sistemden izole akım sensörleri ile ölçümler yapılmıştır. Bu akım sensörleri içerisindeki hall sensör ile kablo içinden geçen akımın endüklediği akıyı ölçerek akımı hesaplamaktadır. Şekil 15'de görüldüğü gibi herbir faz çıkışına bu sensörlerden yerleştirrilmiş ve bu sensörlerin çıkışları kontrol kartının akım ölçümü için seçilen ADC girişlerine şekil 16'de devre şeması ile bağlanmıştır. Kontrol yazılımı içerisinde bu akım değerleri okunmaktadır.

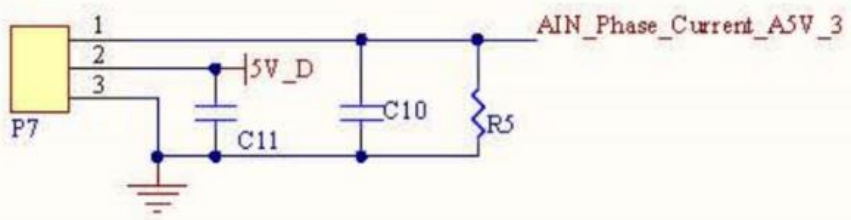

Şekil 16. Her faz için uygulanan LEM akım sensörlerinden gelen sinyalin ADC giriş devresi

\section{Araştırma Sonuçları ve Tartışma}

FDAM'nun bulanık mantık kontrol simülasyon sonuçları şekil 17 'te gösterilmiştir. Şekilden de görüldüğü gibi istenilen referans değere $(500 \mathrm{~d} / \mathrm{dk})$ çok kısa sürede çok az dalgalanma yaparak çıkış referans değere oturmuştur. Fırçasız doğru akım motoru olarak 24V NEMA 17 55W motor tercih edilmiştir. Motor sürücü devresi olarak Texas Instrument firmasının ürettiği 8312 ASIC komponenti kullanılmıştır. Bu sürücü yapısı 50V/3.5 A'e kadar desteklemektedir. Bu sürücü kartının kontrolü için TI TMS 320F28069M mikrodenetleyicisi kullanılmıştır. Bu kontrol ve sürücü kartı şekil 21'de görülmektedir. TI TMS320F28069 DSP ve 8312 sürücü entegreli FDAM sürücü devresi içeren deney düzeneği şekil 22'de görülmektedir. $\mathrm{Bu}$ sistem başarıyla çalıştırılmış ve alınan osiloskop görüntüleri şekil 18, 19, 20’de gösterilmiştir.

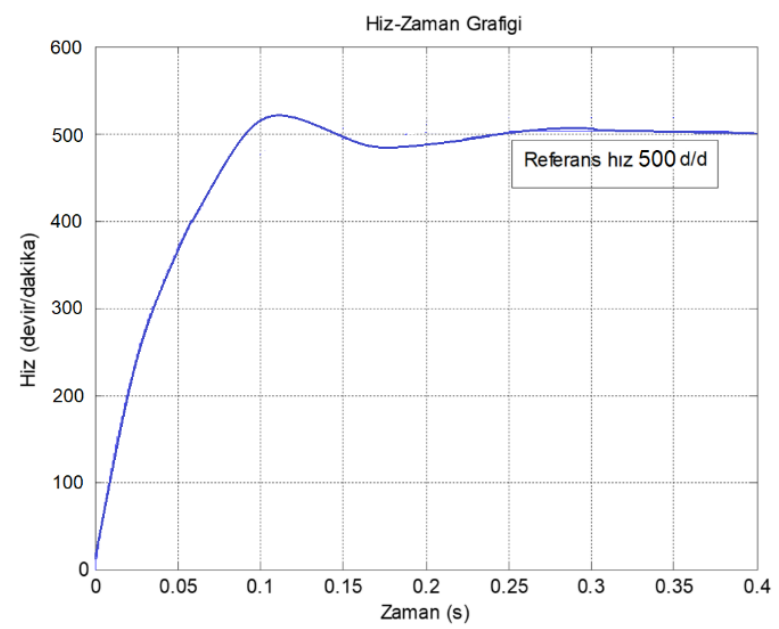

Şekil 17. FDAM'ın bulanık mantık kontrolü simülasyon hız zaman eğrisi

Şekil 18 'de motor yüksüz ve 500 devir /dk ile dönerken fazlar arası V12, V23, V13 gerilimleri görülmektedir. Sinyaller arasında 120'şer derecelik faz farkı bulunmaktadır. Şekil 19'da FDAM birinci fazının V12 gerilimleri ve I1 faz akımı görülmektedir. Şekil 20'de FDAM'ın alan etkili (hall effect) sensör çıkış sinyalleri görülmektedir.

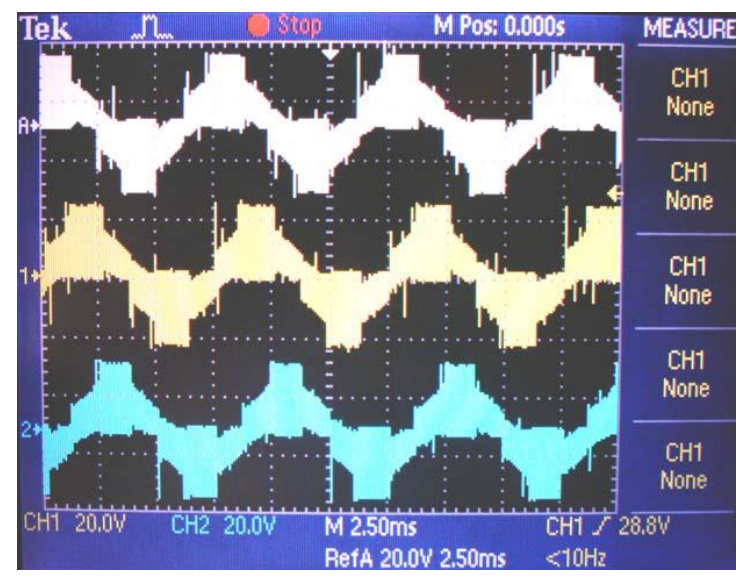

Şekil 18. FDAM fazlar aras1 gerilimler (V12, V23, V13 ) 


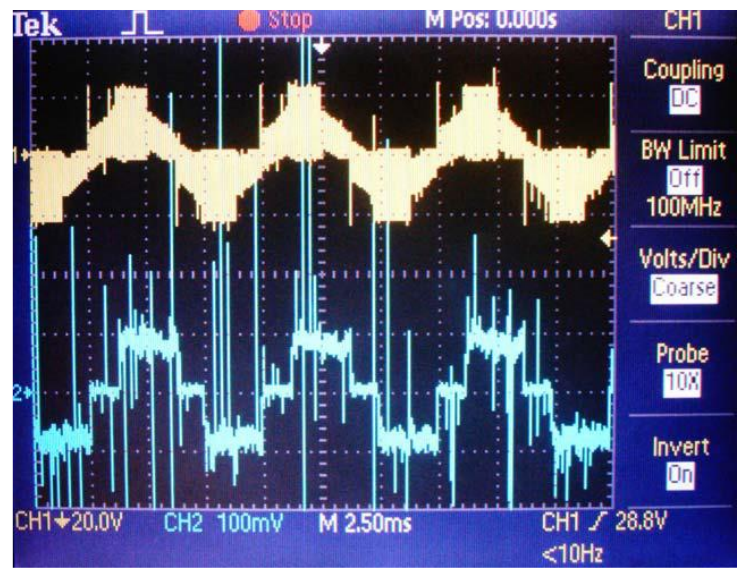

Şekil 19. FDAM birinci fazının V12 gerilimi ve İ1 akımı.

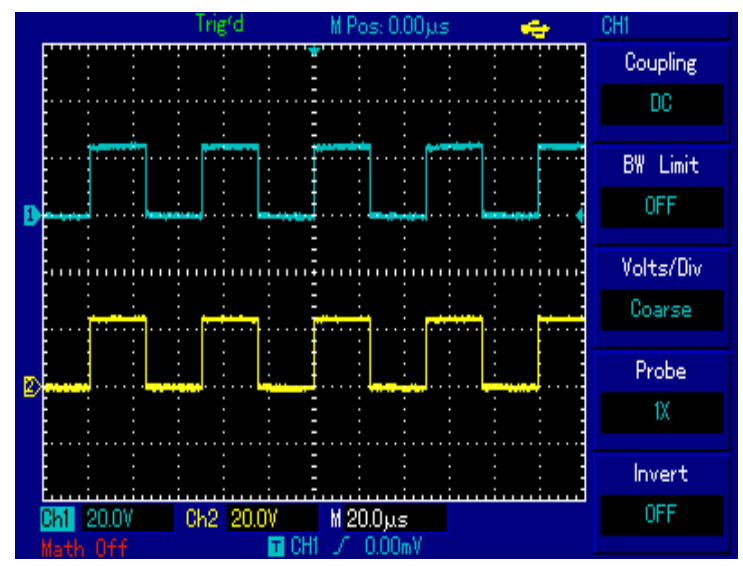
sinyalleri

Şekil 20. FDAM'ın alan etkili (hall effect) sensör çıkış

Şekil 18 ve 19'da FDAM alan etkili (hall effect) sensör HallA, HallB, HallC, çıkış sinyalleri görülmektedir. Şekil 20'de FDAM alan etkili (hall effect) sensör HallA, HallB, HallC, çıkış sinyalleri görülmektedir.

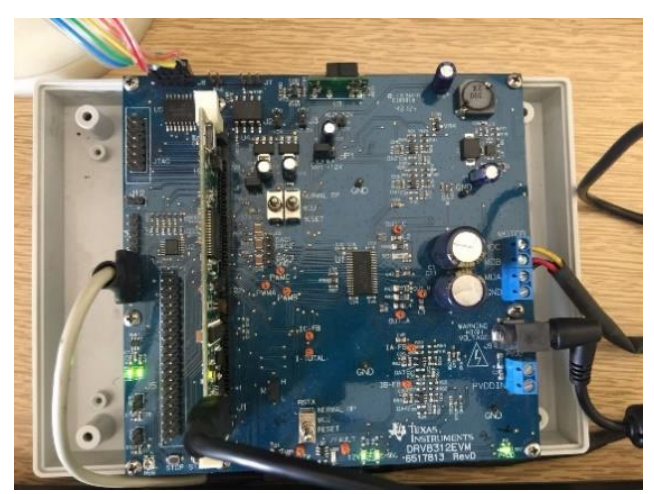

Şekil 21. TI TMS320F28069 DSP ve 8312 sürücü entegreli FDAM sürücü devresi

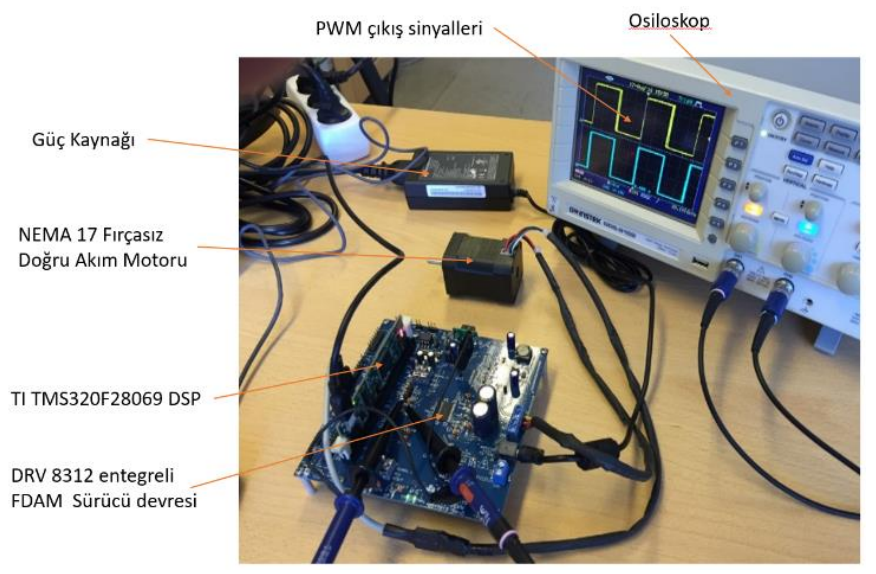

Şekil 22. TI TMS320F28069 DSP ve 8312 sürücü entegreli FDAM PWM çıkışları

\section{Sonuç}

$\mathrm{Bu}$ çalışmada Fırçasız doğru akım motorunun TMS320F28069 DSP tabanlı bulanık mantık kontrolü ile çalıştırılması başarıyla pratik olarak gerçekleştirilmiştir. Sistemin normal kontrol yapılarına göre daha hızlı, kararlı çalıştığ gözlemlenmiştir. Bu sistemde akım, hız ölçümü de yapılmakta olup hız kontrolünün yanında moment kontrolü de yapılmaktadır.

Sonuç olarak, bu bulanık mantık kontrol uygulaması pratik sektör uygulamaları için hızlı, kararlı etkin bir çözüm imkânı sunmuştur. Bundan sonra bu çalıșma sonucunda elde edilen sonuçlar PI, PID, Alan Yön Kontrolü (Feild Orient Kontrol-FOC) Gürbüz (Robust) kontrol gibi farklı kontrol yöntemlerinin sonuçları ile karşılaştırılabilir ve en etkili kontrol sistemi ile ilgili bulgulara ulaşılabilir. (Bu yayın Ali BAHADIR'ın doktora tezinden üretilmiştir. )

\section{Kaynakça}

Abdulhamitbilal E. (2010). İTÜ-Hafif Ticari Helikopter Uçuş Dinamiği, Kararlılık Analizi Ve Geliştirilmiş Kontrol Sistemleri Tasarımı. Doktora tezi, İstanbul Teknik Üniversitesi Fen Bilimleri Enstitüsü, Uçak ve Uzay Mühendisliği Anabilim Dalı,: Uçak ve Uzay Mühendisliği Programi.

Bahadır A., (2021) Elektrikli Araçlar için Firçasiz Doğru Akım Motor Sürücüsü Tasarımı ve Adaptif Kontrolü. Konya Teknik Üniversitesi, Elektrik-Elektronik Mühendisliği Doktora Tezi.

IQ Math on the Texas Instruments TMS320C28x DSP. (2004). Literature Number: PRC087, 2004.

Markovic, M., Hodder, A., Perriard, Y. (2009). An Analytical Determination of The Torque-Speed and EfficiencySpeed Characteristics of a BLDC Motor. Energy Conversion Congress and Exposition (ECCE 2009), 168172.

Moshiri B. and Rashidi F.(2004). Self-tuning Based Fuzzy PID Controllers: Application to Control of Nonlinear HVAC Systems. Intelligent Data Engineering and Automated Learning pp 437-442, IDEAL 2004.

Nair, S.S., Nalakath, S., Dhinagar, S.J. (2011). Design and Analysis of Axial Flux Permanent Magnet BLDC Motor for Automotive Applications. IEEE International Electric Machines \& Drives Conference (IEMDC'11), 1615-1618. 
Park, S.J., Park, H.W., Lee, M.H., Harashima, F. (2000). A New Approach For Minimum-Torque-Ripple MaximumEfficiency Control of Bldc Motor. IEEE Transactions on Industrial Electronics, 47(1), 109-114.

Rahim, N.A.,Hew Wooi Ping, H.W., Tadjuddin, M. (2007). Design of Axial Flux Permanent Magnet Brushless DC Motor for Direct Drive of Electric Vehicle. IEEE Power Engineering Society General Meeting, 1/6.

Simulink, Simulation and Model-Based Design (2020) User's Guide.TMS320F28069 Data Manual. (2004). Literature Number: SPRS174L.

Tuncay, R.N., Üstün, O., Yılmaz, M., Gökce, C., Karakaya, U.(2011). Design and Implementation Of An Electric Drive System For In-Wheel Motor Electric Vehicle Applications. 7th IEEE Vehicle Power and Propulsion Conference (VPPC'11), 1-6.

Tutelea, L.; I. Boldea, I., (2007). Optimal Design of Residential Brushless D.C. Permanent Magnet Motors with FEM Validation. Aegean Conference on Electric Machines, Power Electronics and Electromotion (ACEMP '07), 435439.

Ustun, O., Yilmaz, M., Gokce, C., Karakaya, U., Tuncay, R. N., (2009). Energy Management Method for Solar Race Car Design and Application. IEEE International Electric Machines and Drives Conference, 804-811.

Zarko, D., Ban D., Lipo, T.A. (2007). Analytical Solution for Cogging Torque in Surface Permanent-Magnet Motors Using Conformal Mapping. IEEE Transactions on Magnetics, 44(1), 52-64.

Zhao, L., Ham, C., Zheng, L., Wu, T., Sundaram, K., Kapat, J., Chow, L. (2007). A Highly Efficient 200000 Rpm Permanent Magnet Motor System. IEEE Transactions on Magnetics, 43(6), 2528-2530.

Zarko, D.,Ban, D., Lipo, T.A. (2006). Analytical Calculation of Magnetic Field Distribution in the Slotted Air Gap of a Surface Permanent-Magnet Motor Using Complex Relative Air-Gap Permeance. IEEE Transactions on Magnetics, 42(7), 1828-1837, 2006. 